\title{
Economics of Breeding, Gestating and Farrowing Hogs in "Natural Pork" Production; Financial Comparison
}

\author{
A.S. Leaflet R2165 \\ Denis Reich, Research Assistant, Department of \\ Economics, and James Kliebenstein, Professor, \\ Department of Economics
}

Summary and Implications

Naturally raised pork has become a fast-growing niche market for small mid-western livestock operators. Producer marketing organizations such as Niman Ranch and Eden Natural are working to meet growing demand. While financial numbers have been comprehensively calculated for grow-finish operations in this sector, particularly with hoop production systems being compared to conventional production systems, there has been a lack of information on the breeding and farrowing stages. The objective of this report is to provide an analysis of breeding and farrowing production costs and financial analysis for naturally raised pigs in a hoop production system.

A low investment pork operation typical to that of a Niman Ranch sized operation (100 breeding sows) is utilized for the analysis. The lactating period is 5 weeks with therapeutic use of antibiotics only. We will examine costs per weaner pig for different types of facilities and herd management techniques.

\section{Introduction}

This report provides a budget estimate for producing weaner pigs in a natural, Niman Ranch style operation. While analyzing the sensitivity of both facility investment and herd management techniques, the most influential cost item due to its externally governed nature is labor. A labor cost sensitivity analysis revealed breakeven cost for producing weaners is unlikely to be any cheaper than $\$ 34.63$ per pig (at $\$ 8$ per hour labor) and could be as high or higher (if litter labor demand has been underestimated) than $\$ 39.20$ per pig (at $\$ 15$ per hour labor).

\section{Facility}

\section{Materials and Methods}

Facility choices examined are hoop buildings versus retrofit of an existing barn for breeding and gestating; and hoop and pasture versus the "Swedish" greenhouse type for farrowing. Investment for retrofitted barns is the cost of retrofitting; barns were considered to have zero value before retrofit. Investment levels for structures other than fitted barns were determined by assuming facilities and equipment were newly purchased. Facilities were charged 7.0 percent interest annually on the average total investment or 3.5 percent on initial investment. Depreciation was over 10 years at the rate of 10 percent annually with an additional 1.5 percent charge for insurance and taxes. This results in a 15 percent annual change.

\section{Production Efficiency Assumptions}

Production efficiency information is based on both Niman Ranch requirements for farrowing and breeding, feeding and weaning and Iowa State University hoop group research. The key assumptions are as follows:

- Facility cost information was retrieved from what was available from farmers, extension and previous papers reporting on costs. Facility information on the Swedish Greenhouse was obtained directly from Jude Becker - an independent organic hog farmer from Dyersville, IA. The Hoop and Pasture hut information was from previous studies done by Ben Larson, Pete Lammers and other members of the hoop group. Barn retrofit was estimated with help from Professor Jim Kliebenstein and Niman Ranch personnel.

- Depreciation period was over 10 years. The interest rate on investment was 7 percent, or an annual investment average of 3.5 percent. Taxes and insurance were estimated at 1.5 percent. The result being an annual fixed cost of 15 percent on the initial investment.

- Manure handling investment cost was $\$ 6000$ (two spreaders at \$3000 each) was included in the initial (facility) investment. This was depreciated with the facility investment(s).

- An up-front cost of $\$ 24,450$ for miscellaneous items such as a tractor, feed storage and fourwheelers was included in the initial (facility) investment. This was depreciated with the facility investment(s).

- Replacement gilts were priced at $\$ 175$, while gilt finishing for internal replacement was fixed at $\$ 40$. Production life was fixed at 3 years. 
- $\quad$ Boars were priced at $\$ 750$ each with a production life of 3 years. Feed costs for boars were included for a light mating regimen. AI was priced at $\$ 5.50$ per dose and 2.75 doses per sow per breeding period.

- Cull Revenue was not included in the operating cost analysis.

- $\quad$ There were 2 groups of sows, each farrowing approximately 2 times per year. Conception rate was 88 percent. Litter size was 7.49 weaners per litter from data provided by hoop group studies. There were up to three breeding attempts per gilt and two per sow before culling.

- Gestation period was 114 days. Farrowing duration was 5 weeks with an average dry period, post-farrow of 4 days before breeding again.

- Feed rations were based on a standard ISU extension diet of corn, 44 percent soybean meal (SBM) and premix. Feeding rates of $2.8 \mathrm{lbs}$ per sow per day for gestation and $22.6 \mathrm{lbs}$ per sow per day for farrowing were derived from Hoop group studies on sub therapeutic use of antibiotics (Larson, Kliebenstein, 1999).

- $\quad$ Prices for feed are based on a 5-year rolling average for feed grain in Iowa (John Lawrence, 2005).

- $\quad$ Additional marketing, veterinary and bedding costs were \$3.61 per weaner.

\section{Feed Cost Information}

Feed is the most significant cost in the operation. Ration costs were $\$ 0.044$ per pound for gestation and $\$ 0.054$ per pound for farrowing and lactation. By comparison these costs were $\$ 0.051$ and $\$ 0.058$ respectively in a previous study (Larson, Kliebenstein, 1999). Total feed costs, usage and efficiencies are presented in Table 2.

Information on diet cost is provided in Table 3. They are derived from previous studies (Larson, Kliebentstein 1999) and with additional consultation from Professor Mark Honeyman and Pete Lammers of the hoop group at Iowa State. Cost information was obtained from pricing information supplied on Dr. John Lawrence's personal homepage, previous cost estimates (Larson, Kliebenstein, 1999) and consultation with Dr. Honeyman. Diet Costs were based on a rolling 5-year average price for the respective ingredients.

\section{Facility Investment}

Total facility and equipment investment for gestation and breeding is $\$ 62,650$ with hoop structures versus $\$ 35,515$ for a barn retrofit; and for farrowing is $\$ 47,612$ with a combination of pasture and (winter) hoop farrowing versus $\$ 99,504$ for the "Swedish" greenhouse system (Table 1). The more affordable facility choices of a retrofitted barn for gestation and the combination of hoop and pasture for farrowing resulted in annual fixed cost total of $\$ 12,470$ or $\$ 8.32$ per weaner pig.

\section{Herd Investment and Operating Costs}

Breeding and gestating investment costs are provided in Table 4. Gilt prices were $\$ 175$ and growing costs for home raised gilts used to replenish the breeding herd were $\$ 40$. Gilt replacement using both internal and external replacement options are examined as well as use of artificial insemination (AI) versus boar breeding. Using replacement gilts and AI, annual investment cost would be $\$ 10,724$. Using home raised gilts would result in an annual investment $\$ 5,415$, a gross saving of $\$ 5,309$. This comparison does account for finishing internally recovered gilts from the weaner stage but does not account for the hidden cost of not marketing them as weaner pigs. Changing to natural breeding (and remaining with replacement gilts) would mean a total annual operating cost of $\$ 7,918$, a gross saving of $\$ 2,806$. This comparison does not account for the increased labor and maintenance costs of managing breeding boars.

\section{Production Costs}

Production costs for the natural pork production system are presented in Table 5. Bedding use reflects use levels from current research with hoop buildings at Iowa State University, particularly the Rhodes Research Farm with bedding costs added for farrowing. Heating was averaged from a series of studies by Pete Lammers regarding deep-bedded systems in Iowa with additional input from Jude Becker from Dyersville, Iowa. Medical costs were again obtained from previous research and were based on non-subtherapeutic use of antibiotics as per Swedish studies (SOU, 1997). Total annual production cost amounted to $\$ 15,291$ or $\$ 10.20$ per weaner pig.

Table 6 outlines the completed budget for natural pork production in the weaner pig stage. Labor cost and marketing cost are included to complete the analysis. Calculations are based on a producer using purchased replacement gilts and AI breeding at a labor rate of $\$ 10$ per hour at 5 hours per litter. This combination was chosen since using combinations 
with home raised gilts and natural breeding represented a significant amount of uncalculated hidden costs already evident in Table 2. Total annual cost of production comes to $\$ 49,769$ or a cost of $\$ 33.22$ per raised weaner pig.

\section{Labor Sensitivity Analysis}

Labor and feed costs are the two most influential cost items in this analysis. Labor cost has the distinction of being somewhat more flexible within the operator's management strategy; hence a sensitivity analysis was performed on a more typical selection of facilities and herd management options to test for its influence on the cost of producing a weaned pig. Cost parameters for the analysis remained consistent with the completed budget and included a barn retrofit for breeding and pasture huts with hoop barn(s) for farrowing. Gilts were purchased as replacements and AI was used for breeding. Assuming a total of 5 hours of labor per litter, operating costs would range from $\$ 23.59$ per weaned pig at $\$ 8$ per hour of labor to $\$ 34.63$ per weaned pig at $\$ 15$ per hour of labor $(\mathrm{TVC}=0.653 \mathrm{~L}$ $+18.37)$. Including facility costs the same variance in labor costs would result in a total cost per weaned pig ranging from $\$ 34.63$ up to $\$ 39.20$ (TC $=0.653 \mathrm{~L}$ +29.40 ). It is a significant assumption that labor demands are equal for all herd management options. For instance labor demands on natural breeding are likely to be measurably different to those required for $\mathrm{AI}$; hence further research is needed to examine the differences in labor needed for these options.

Figure 1. Sensitivity Analysis* - Labor Cost on Operating and Tota Cost for Alternate Breeding, Gestation and Farrowing per weaned pig

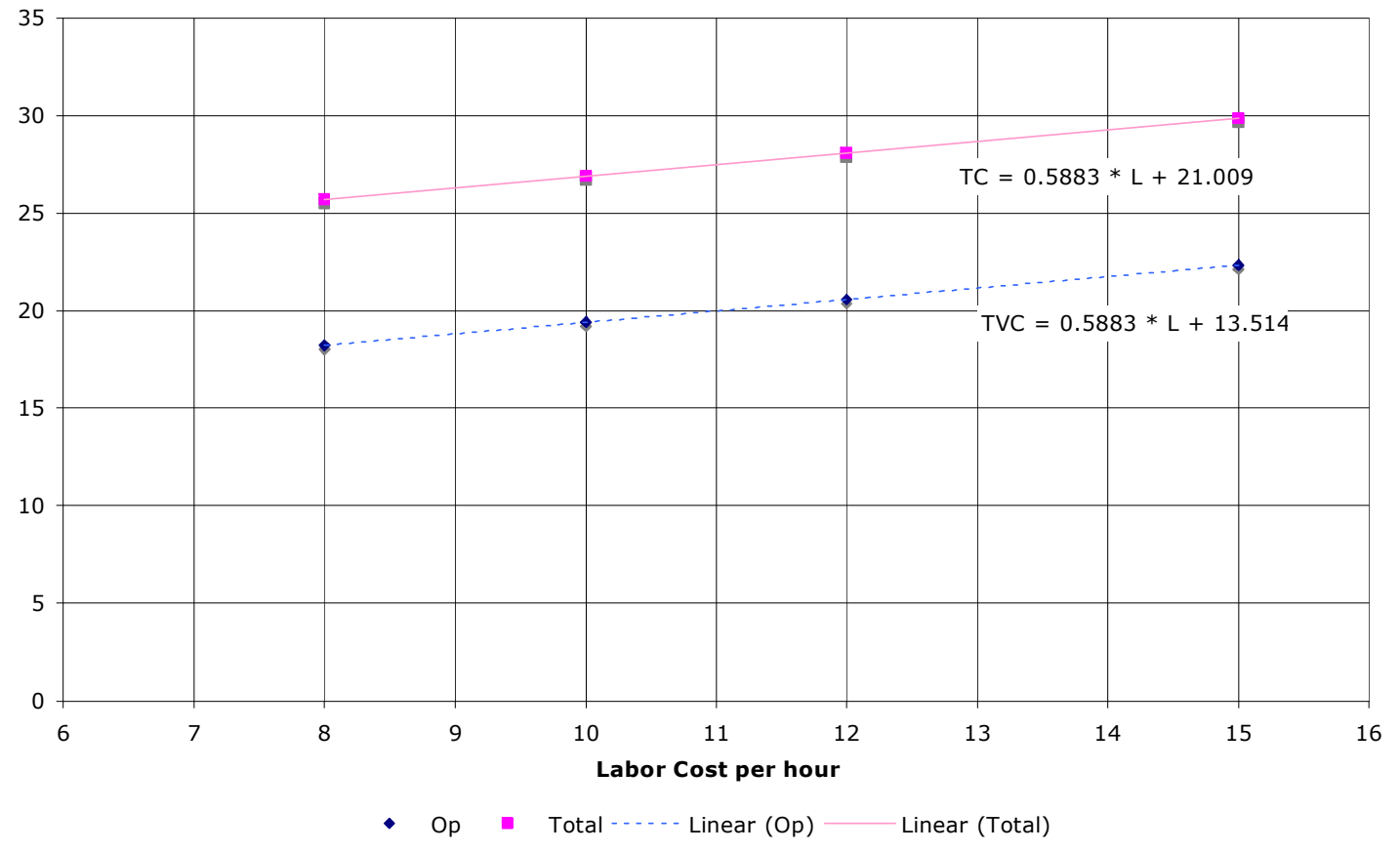


Table 1 . Facility Investment.

\begin{tabular}{|l|c|c|c|c|}
\hline \multirow{2}{*}{\multicolumn{1}{|c|}{ Nature of Cost }} & \multicolumn{2}{|c|}{ Breeding/Gestating } & \multicolumn{2}{c|}{ Farrowing } \\
\cline { 2 - 5 } & Hoop & Barn Retrofit & Hoop/Pasture & Greenhouse \\
\hline Total Facility Cost & $\$ 47,425$ & $\$ 20,290$ & $\$ 32,387$ & $\$ 84,279$ \\
\hline Manure Handling & \multicolumn{3}{|c|}{$\$ 3,000$} \\
\hline Miscellaneous & \multicolumn{3}{|c|}{$\$ 12,225$} \\
\hline Total Initial Investment & $\$ 62,650$ & $\$ 35,515$ & $\$ 47,612$ & $\$ 99,504$ \\
\hline Annual Cost on Investment* & $\$ 9,398$ & $\$ 5,328$ & $\$ 7,142$ & $\$ 14,926$ \\
\hline
\end{tabular}

* This is 15 percent of total initial investment

Table 2. Feed cost and usage breakdown.

\begin{tabular}{|l|c|c|c|}
\hline Item & Gestation & Farrowing/Lactation & Boar \\
\hline Duration (days) & 114 & 35 & 365 \\
\hline Turns per year & \multicolumn{2}{|l|}{1.957} & - \\
\hline Annual Duration (weeks) & 31.9 & 9.79 & 52.1 \\
\hline Lbs/sow-boar/day & 2.8 & 22.6 & 5.7 \\
\hline Cost (per sow/boar) & $\$ 26.96$ & $\$ 82.73$ & $\$ 136.79$ \\
\hline Cost (per weaner) & $\$ 2.05$ & $\$ 6.30$ & $\$ 0.37$ \\
\hline Cost (per lb) & $\$ 0.044$ & $\$ 0.054$ & $\$ 0.088$ \\
\hline Total Cost/yr (100 working sows) & $\$ 3,074$ & $\$ 9,432$ & $\$ 547.14$ \\
\hline
\end{tabular}

Table 3. Diet breakdown.

\begin{tabular}{|l|c|c|c|c|c|}
\hline \multirow{2}{*}{ Component } & \multicolumn{2}{|c|}{ Average } & \multicolumn{3}{c|}{ Lbs per ton } \\
\cline { 2 - 6 } & $\$ /$ ton* & $\$ /$ pound & Gestating & Lactating & Boar \\
\hline Corn-meal & $\$ 1.98$ & $\$ 0.033$ & 858 & 737 & 720 \\
\hline Soybean-meal & $\$ 180.57$ & $\$ 0.090$ & 100 & 230 & 920 \\
\hline Whey & $\$ 432.77$ & $\$ 0.22$ & 0 & 0 & 300 \\
\hline Premix & $\$ 120$ & $\$ 0.060$ & 42 & 33 & 60 \\
\hline \hline Diet cost per ton & - & - & $\$ 87.68$ & $\$ 102.10$ & $\$ 175.32$ \\
\hline Diet cost per pound & - & - & $\$ 0.044$ & $\$ 0.054$ & $\$ 0.088$ \\
\hline
\end{tabular}

*2000 pound ton.

Table 4. Herd Investment Costs.

\begin{tabular}{|l|c|c|c|c|}
\hline \multirow{2}{*}{ Nature of Cost } & \multicolumn{2}{|c|}{ Gilts } & \multicolumn{2}{c|}{ Boars } \\
\cline { 2 - 5 } & Home Raised & Purchased & Natural & AI \\
\hline Annual Investment* & $\$ 1,520$ & $\$ 6,650$ & $\$ 1,000$ & $\$ 3,711$ \\
\hline Interest (3.5 percent) & $\$ 54$ & $\$ 233$ & $\$ 35$ & $\$ 130$ \\
\hline Total Annual Investment & $\$ 1,574$ & $\$ 6,883$ & $\$ 1,035$ & $\$ 3,841$ \\
\hline Total Cost Difference & $(\$ 5,309)$ & - & $(\$ 2,806)$ & - \\
\hline
\end{tabular}

* For 3 year working life at approximately 2 turns per year and 50 percent of breeding sows bred per turn. 
Table 5. Production Costs.

\begin{tabular}{|l|c|}
\hline Nature of Cost & Annual Cost \\
\hline Bedding & $\$ 746$ \\
\hline Heating & $\$ 350$ \\
\hline Feed & $\$ 13,053^{*}$ \\
\hline Vet/Med & $\$ 278$ \\
\hline Interest (3.5 percent p.a.) & $\$ 865$ \\
\hline Total Annual Operating Cost & $\$ 15,291$ \\
\hline
\end{tabular}

* Natural Breeding would require one more boar at an increased feed rate adding $\$ 183$ to this figure.

Table 6. Total Annual operating Cost Budget*.

\begin{tabular}{|l|c|}
\hline Nature of Cost & Annual Cost \\
\hline Facility Investment & $\$ 12,470$ \\
\hline Fixed Cost per weaner pig & $\$ 8.32$ \\
\hline \hline Herd Investment & $\$ 10,724$ \\
\hline Production Costs & $\$ 15,291$ \\
\hline Labor (at \$10 per hour)** & $\$ 9,786$ \\
\hline $\begin{array}{l}\text { Marketing } \\
\text { (at } \$ 1 \text { per weaner) }\end{array}$ & $\$ 1499$ \\
\hline Total Operating Cost & $\$ 21,972$ \\
\hline Combined Herd Operating Cost & $\$ 37,300$ \\
\hline Total Operating Cost per weaner pig & $\$ 24.90$ \\
\hline \hline Total Annual Cost of Production & $\$ 49,769$ \\
\hline \hline Total Budget Cost per weaner pig & $\$ 33.22$ \\
\hline
\end{tabular}

* With 100 breeding sows and, facility: barn retrofit with pasture/hoop, and herd: purchased replacement gilts with AI.

** 5 hours of labor per litter. 
Iowa State University does not discriminate on the basis of race, color, age, religion, national origin, sexual orientation, gender identity, sex, marital status, disability, or status as a U.S. veteran. Inquiries can be directed to the Director of Equal Opportunity and Diversity, 3680 Beardshear Hall, (515) 294 - 7612 . 